\title{
Radiocarbon Analysis of Microbial RNA to Determine Carbon Sources in Arsenic Contaminated Pleistocene Aquifers in Bangladesh
}

Madeleine Killough, Katharine Scanlan, Brian Mailloux, Alexander van Geen

Tasbiha Chowdhury

Benjamin C. Bostick, M. Rajib Hassan Mozumder, Tyler Ellis

Imtiaz Choudhury, Kazi Matin Ahmed

Bruce Buccholz
Environmental Sciences, Barnard College, New York, NY

Department of Engineering, Smith College, Northampton, MA

Lamont-Doherty Earth Observatory, Columbia University, New York, NY

Department of Geology, University of Dhaka, Dhaka, 1000, Bangladesh

Center for Accelerator Mass Spectrometry, Lawrence Livermore National Laboratory, Livermore, CA 


\section{Geogenic As and Iron Reduction}

- Geogenic As

- Naturally occurring

(a) Iron-reducing bacteria

- Prevalent in Southeast Asia

- Health effects:

- Cardiovascular disease

- Skin lesions

- Cancers (skin, lungs, liver)

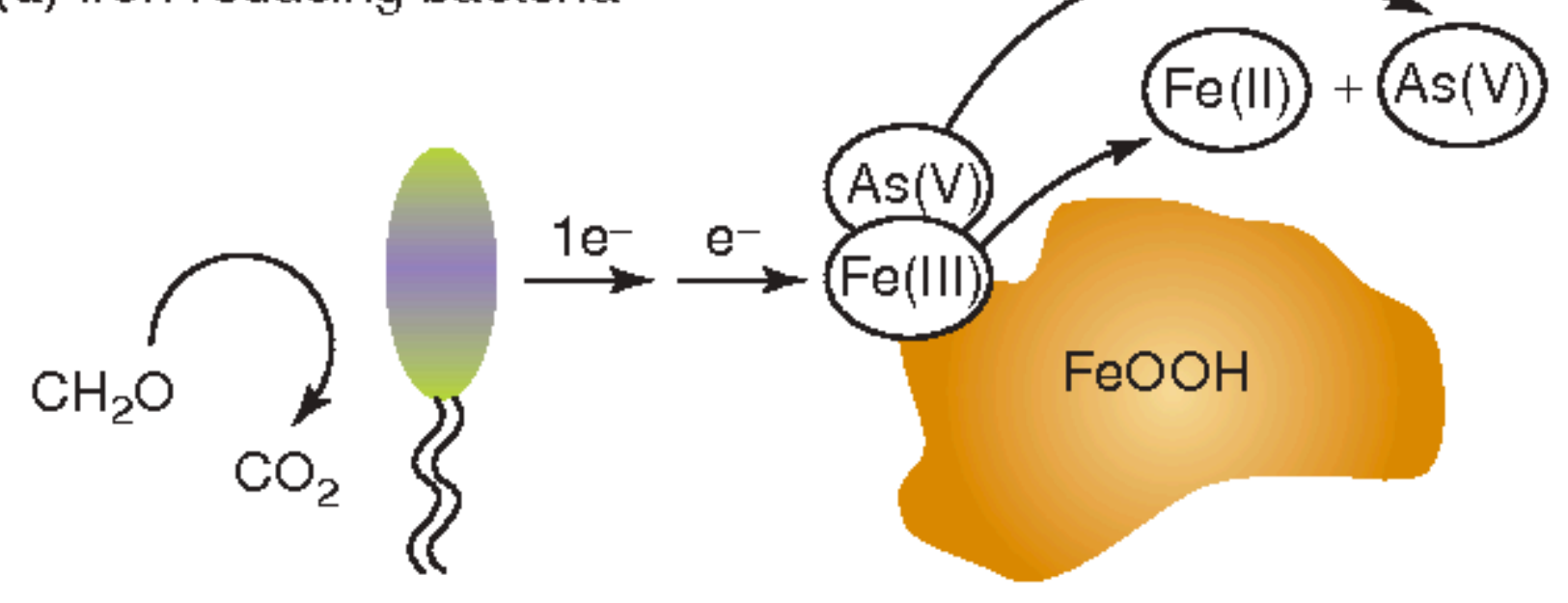

- As release through iron reduction

- Fe III $\rightarrow$ Fe II

-Where is the organic carbon coming from? 


\section{As Contamination of Shallow, Pleistocene Aquifer}

- Shallow wells:

- $<40 \mathrm{~m}$

- Draws from Holocene aquifer

- Cheap and easy to drill

- As levels $>10 \mu \mathrm{g} / \mathrm{L}$

- Intermediate wells:

- 40 - 150m

- Draws from Pleistocene aquifers

- Cheap and easy to drill

- Generally lower As (<10 $\mu \mathrm{g} / \mathrm{L})$

- Some As contamination (>10 $\mu \mathrm{g} / \mathrm{L}$ )

- Deep wells:

- $>120 \mathrm{~m}$

- Expensive to drill

- Low As (<10 $\mu \mathrm{g} / \mathrm{L})$

\section{Arsenic $\left(\mu g \mathrm{~L}^{-1}\right)$}






\section{Potential Carbon Sources}

\section{Bacterial Reduction} of Sedimentary As

\section{Extraction and} Radiocarbon Dating

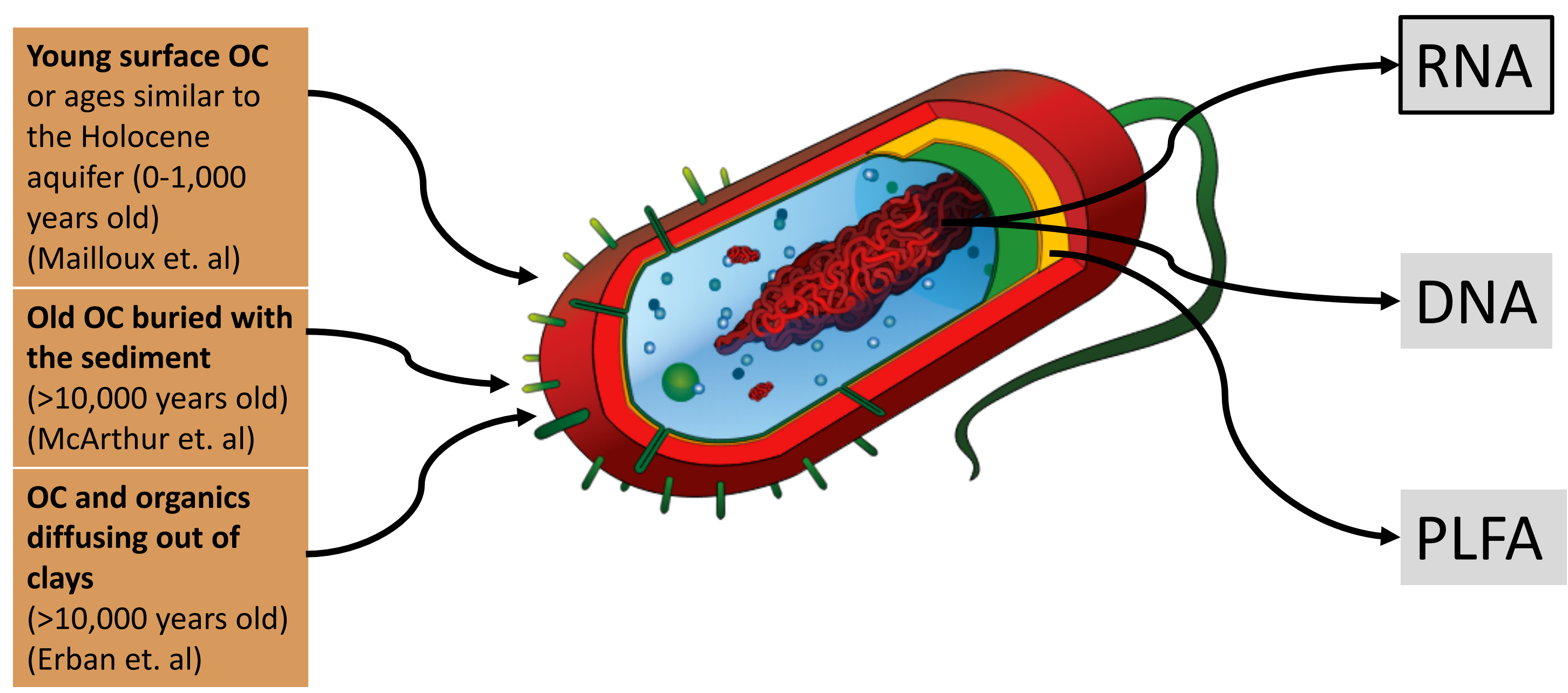




\section{Pleistocene wells $>30$ meters}
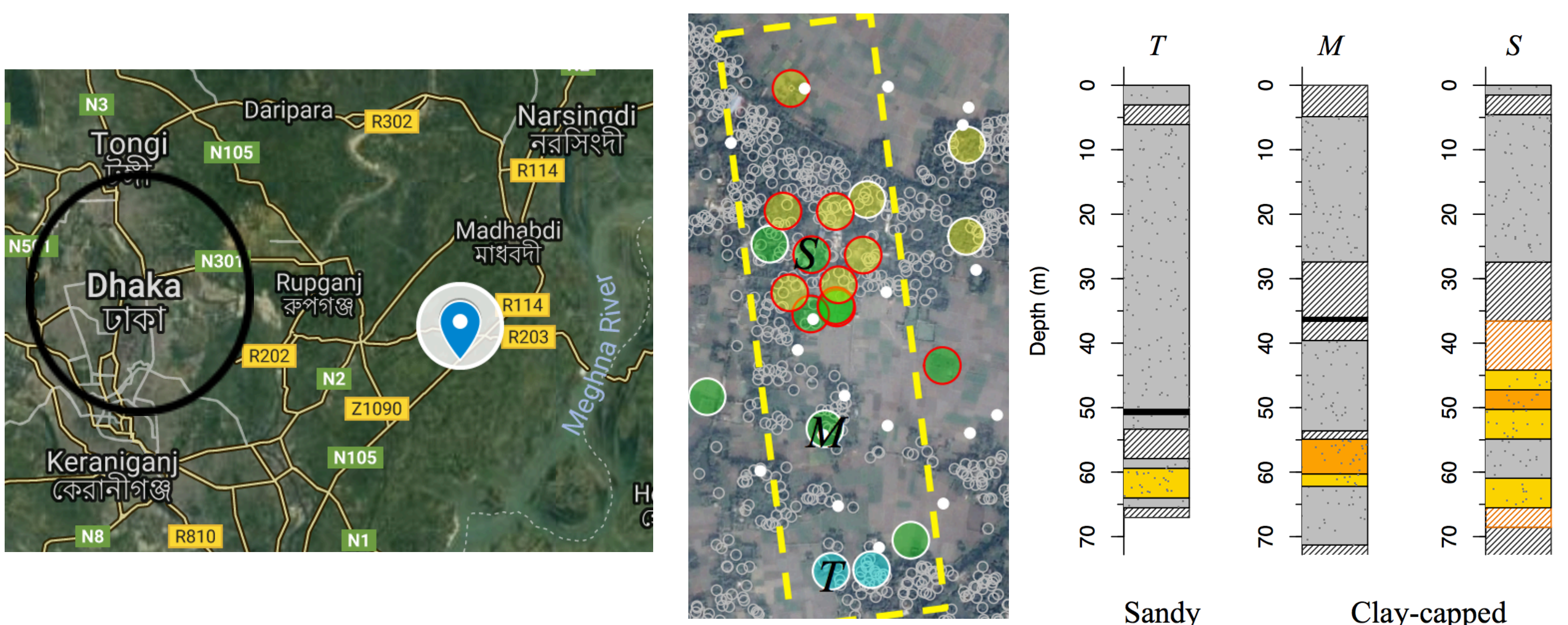

Sandy

Clay-capped 


\section{Possibilities for Carbon Movement at Site M:}

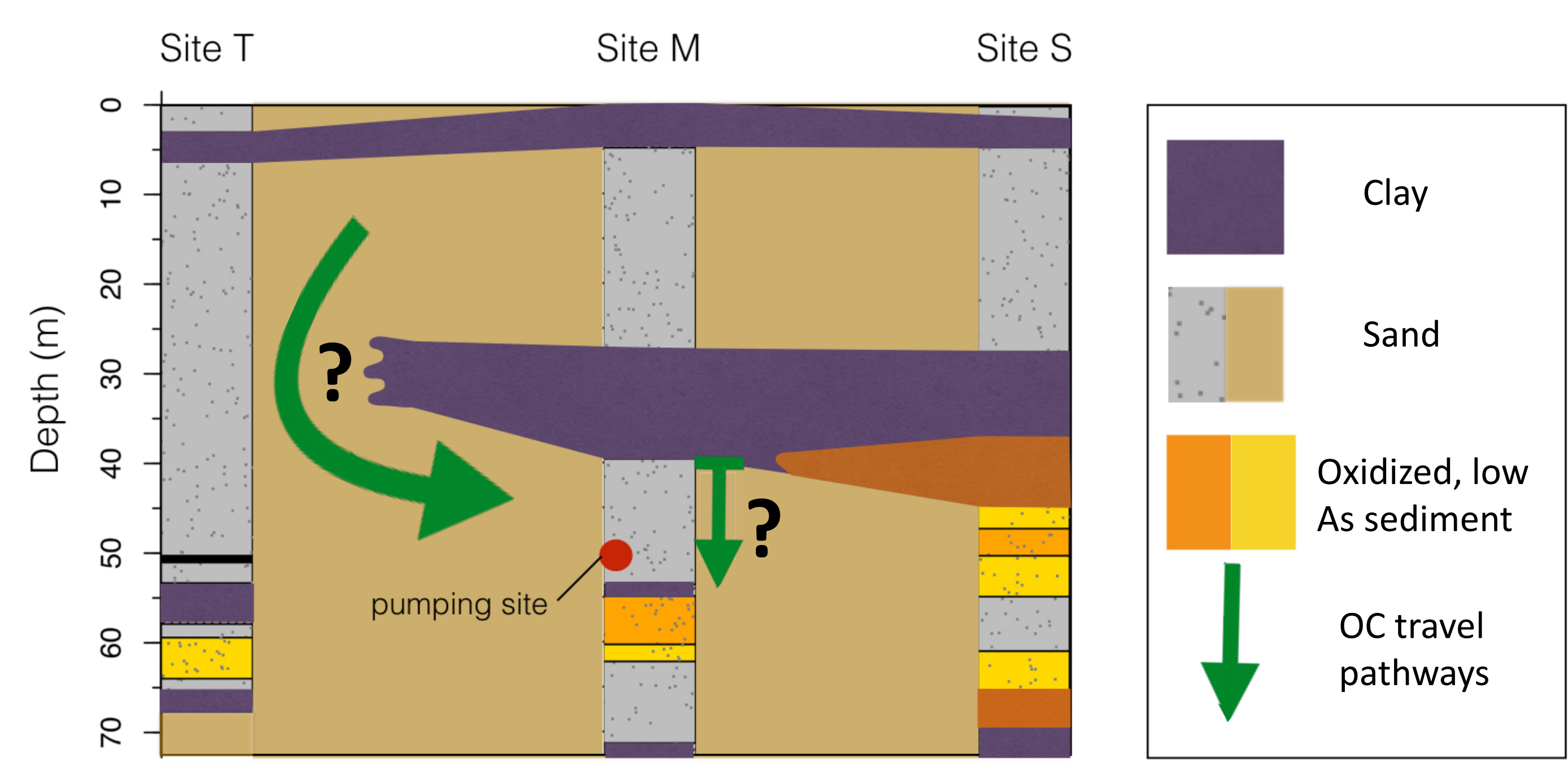




\section{Arsenic Measurements at Site M:}

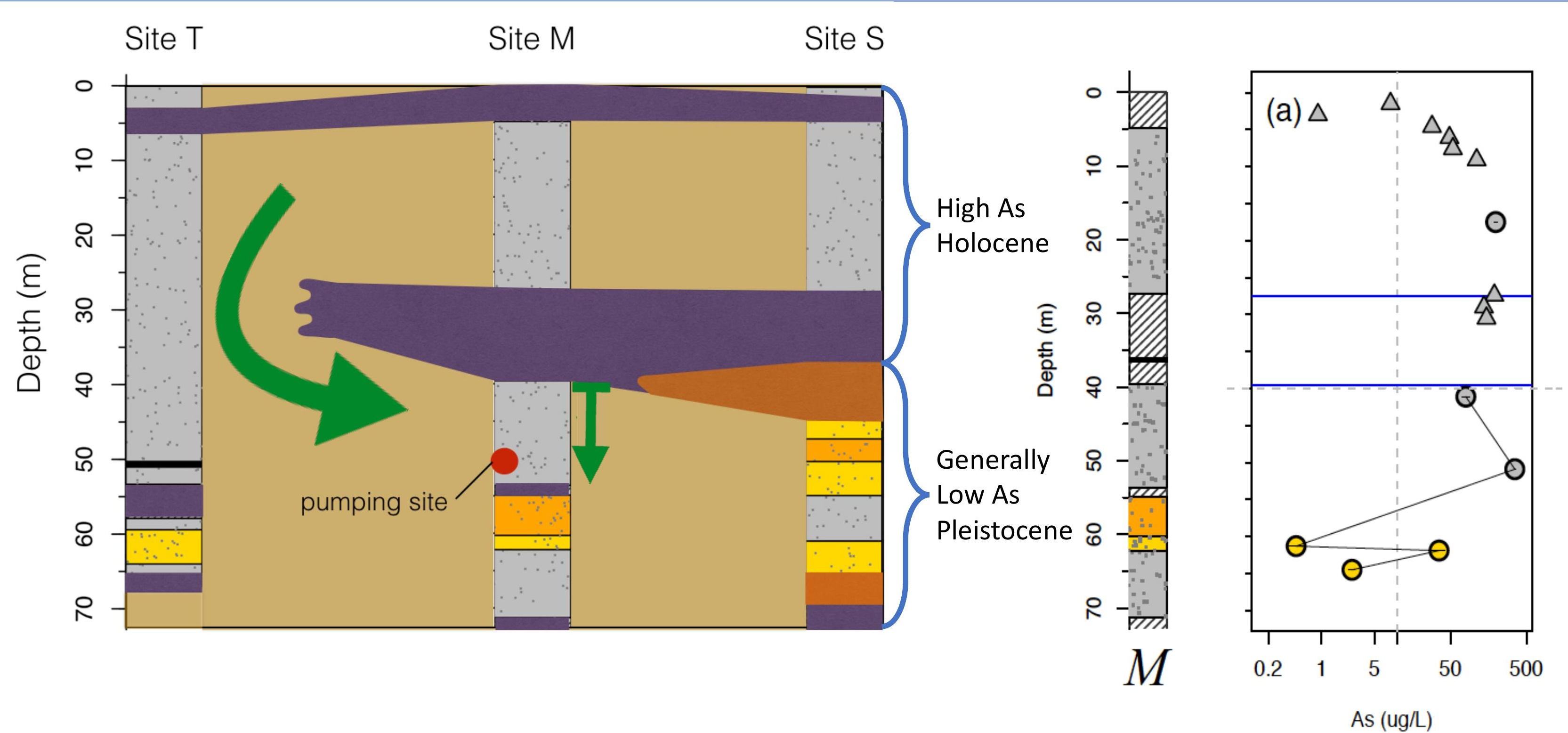




\section{Extraction Methodology}

- 33,860 liters pumped at Site M1.4A

- Filter cut in half to create duplicates

- Cell lysis, Tris-saturated Phenol

Chloroform (1:1), LiCl precipitation

- Radiocarbon dated at LLNL

- Extensive E. Coli testing reproduced end member modern dates

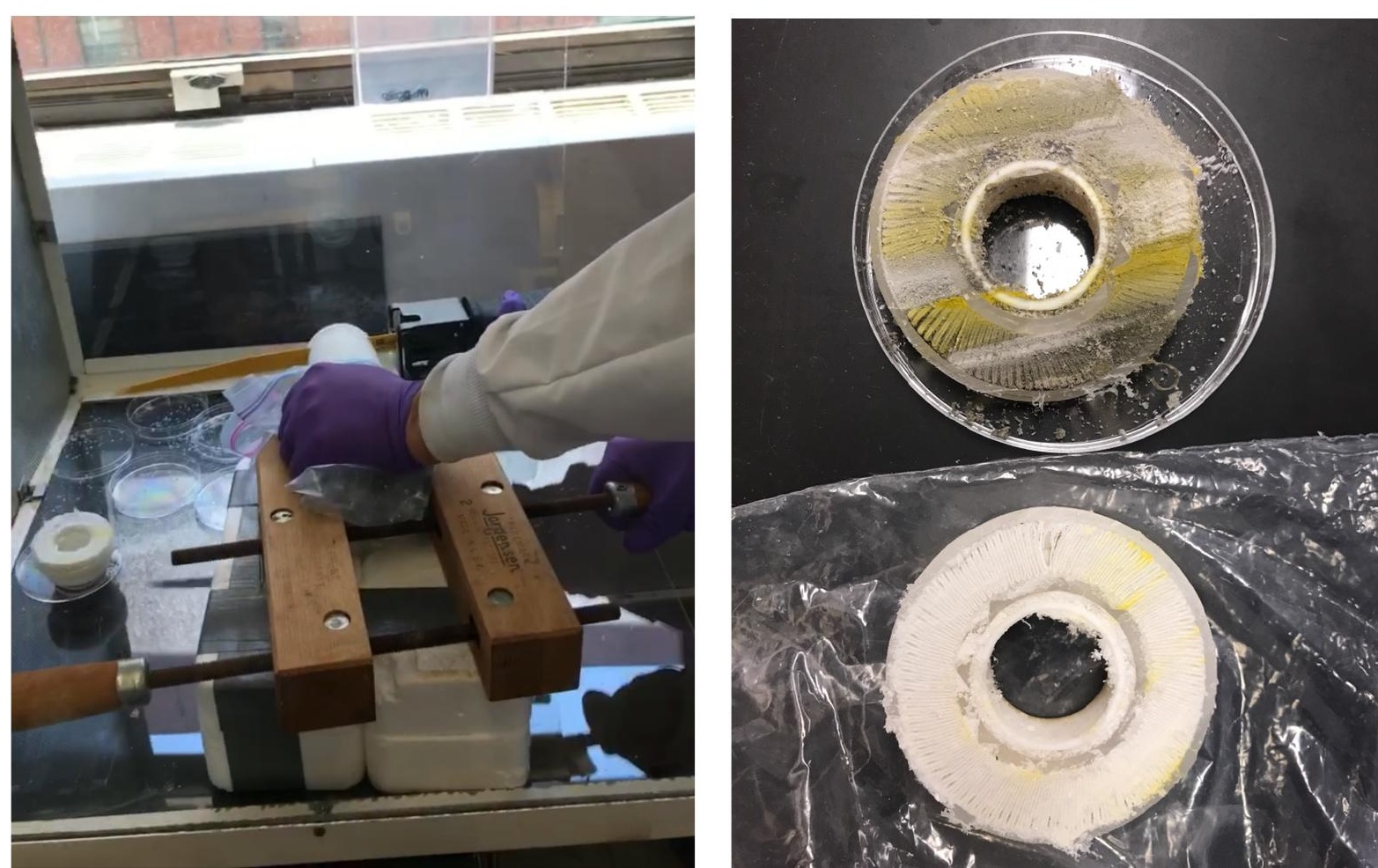




\section{RNA Radiocarbon Dates from Pleistocene Aquifer $<1,000$ years old}

\begin{tabular}{c|c|c|}
$\begin{array}{c}\text { Sample } \\
\text { Name }\end{array}$ & $\Delta^{14} \mathrm{C}$ & ${ }^{14} \mathrm{C}$ Age \\
\hline RNA (1) & $-111.4 \pm 20.1$ & $880 \pm 190$ \\
\hline RNA (2) & $-121.8 \pm 6.2$ & $980 \pm 60$
\end{tabular}




\section{Comparison of RNA, DOC, $\mathrm{CH}_{4}$ Radiocarbon Ages}

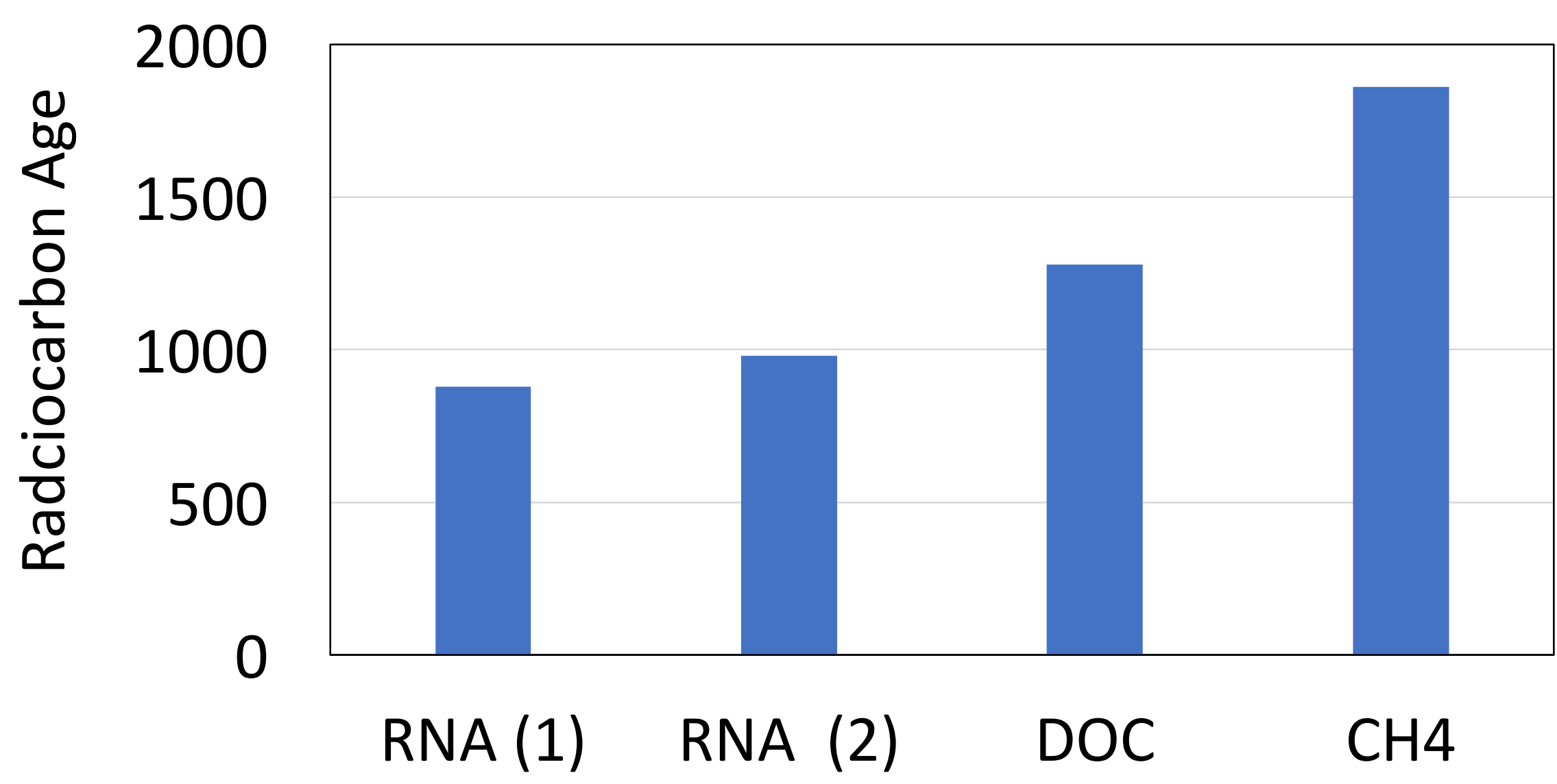

- Site $M$ sediment $(50.6 \mathrm{~m})=>10,000$ years old

- Site M DIC (54.5 m) $=1,050$ years old

Samples from Site M1.4A (51 meters) 


\section{Young Dates Support Advection of Surface OC Around Clay
to the Pleistocene Aquifer Young Dates Support Advection of Surface OC Around Clay
to the Pleistocene Aquifer \\ (a) \\ (1)}
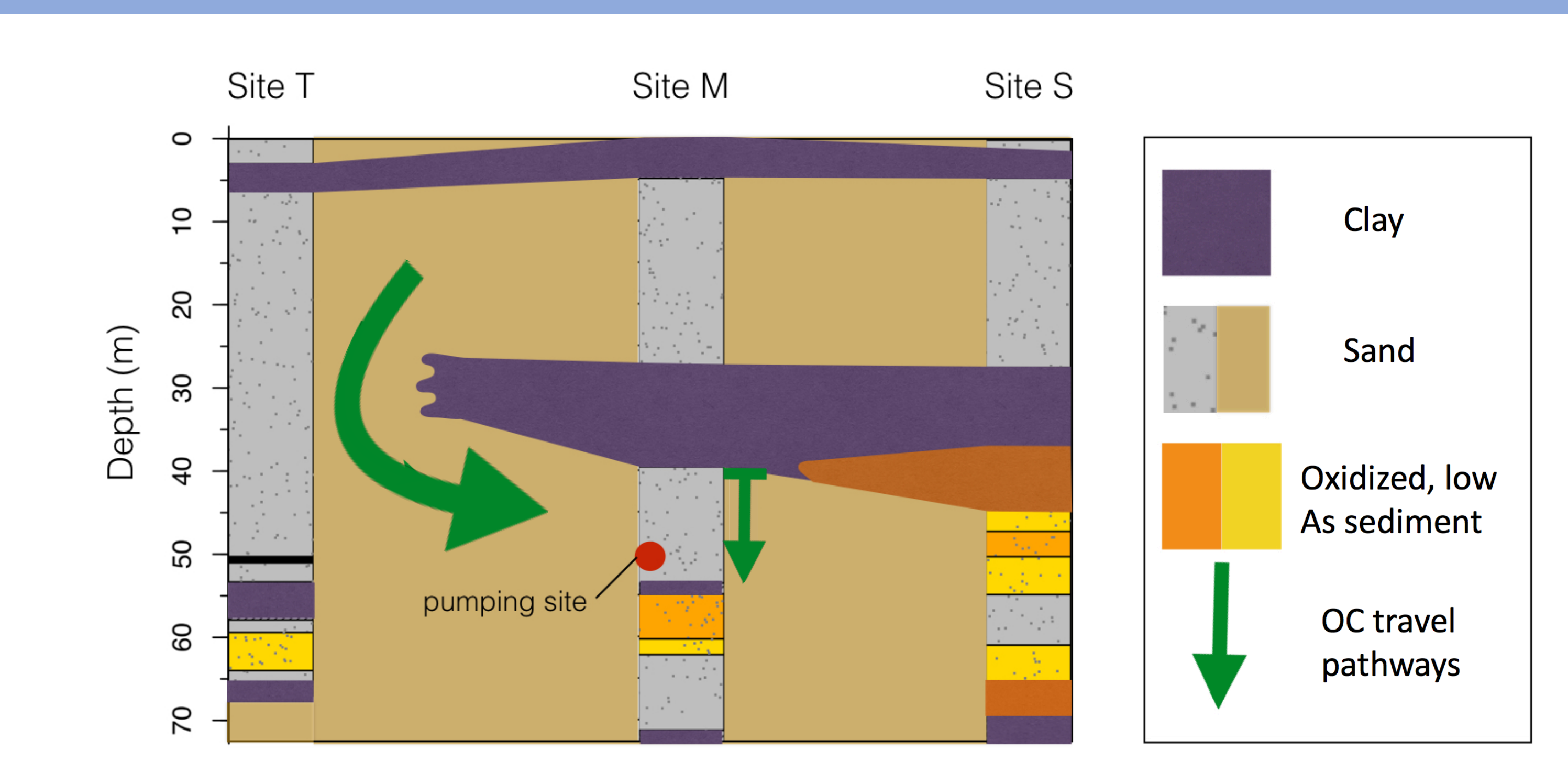

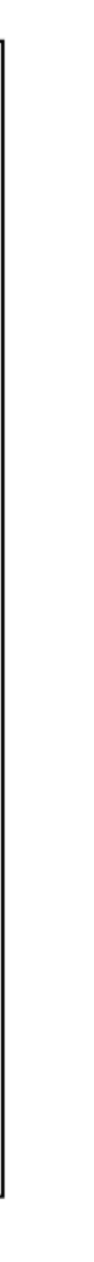






\section{Young Dates Support Advection of Surface OC Around Clay
to the Pleistocene Aquifer Young Dates Support Advection of Surface OC Around Clay
to the Pleistocene Aquifer}
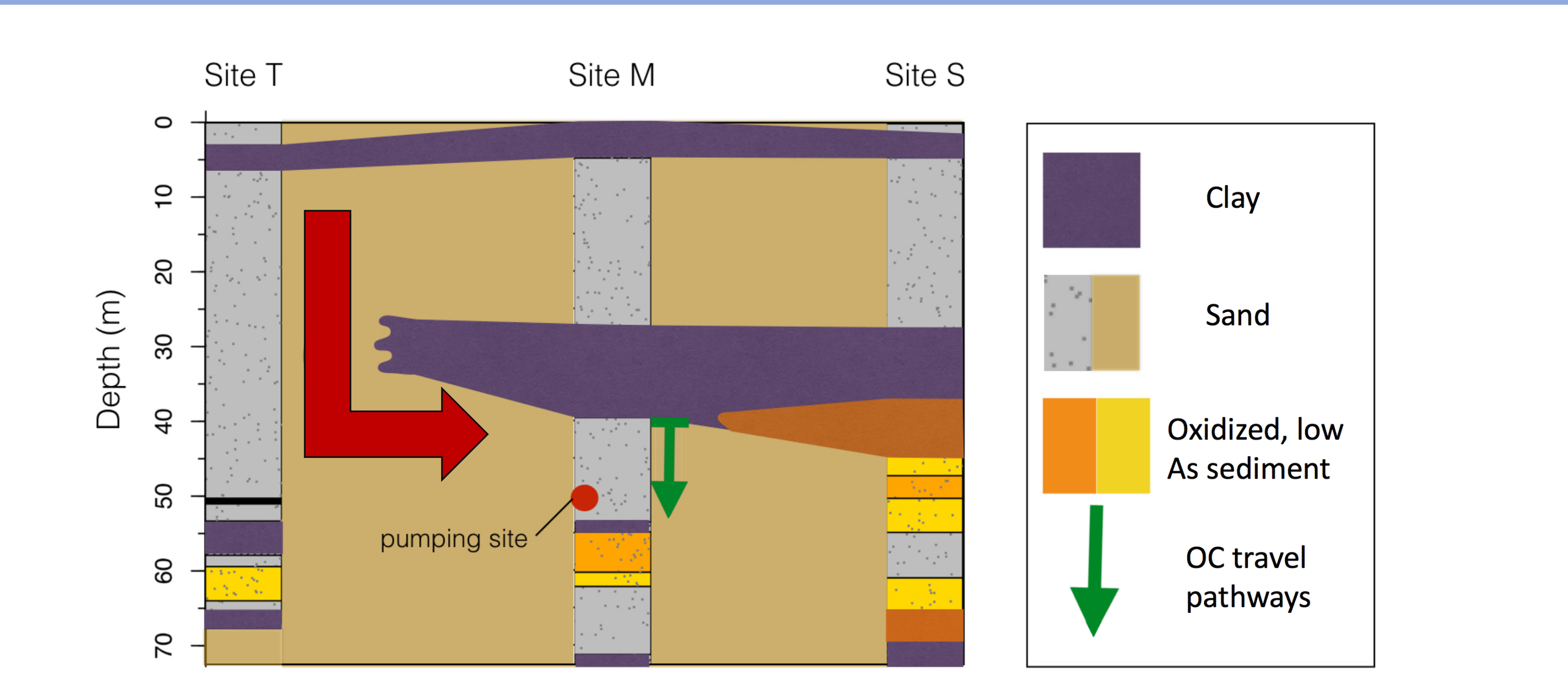


\section{Conclusions:}

- Duplicates worked

- RNA dates $<1000$ years

- Younger than sediment and in situ carbon sources

- Young OC transported around the clay

- Long term stability of Pleistocene aquifers may be compromised by the transport of young OC down to Pleistocene depths, possibly due to groundwater pumping 


\section{Acknowledgements}

- Brian Mailloux

- Katharine Scanlan

- Tasbiha Chowdhury

- Alexander van Green

- Benjamin Bostick

- Rajib Mozumder

- Tyler Ellis

- Imtiaz Choudhury

- Kazi Ahmed

- Bruce Buccholz
- Columbia University

- Barnard's Summer Research Institute

- Earth Intern Program

- Columbia University Earth Institute

- Mailloux Lab

- Van Geen Lab

- Bostick Lab

- Dhaka University and Students

- NIEHS 
